\title{
Genetic Diversity and Characterization of Pigeon Pea Germplasm
}

\author{
H. N. Patel ${ }^{*}$ and D. G. Patel \\ NARP, Agricultural Research Station, Navsar Agricultural University, \\ Bharuch, Gujarat, India \\ *Corresponding author
}

A B S T R A C T

Keywords

Pigeonpea,

Germplasm,

Genetic diversity,

Yield

Article Info

Accepted:

20 November 2020

Available Online:

10 December 2020
The study is planned to study variability, genetic divergence and characterization of pigeonpea germplasm at NARP, Agricultural Research Station, Navsari Agriculture University, Bharuch. Two genotypes i.e. NP 09-41 and NP-09-46 recorded white colour and the same genotypes are identified as high yielder too. While other genotypes are light, reddish or dark brown in colour These traits can be used for identifying individual germplasm. Ten genotypes were grouped into two major clusters. Five genotypes grouped under Ist cluster and the another five genotypes grouped under IInd cluster. NP-09-46, 43, 49, 47 and 50 falls under first cluster while NP-09-41, 48, 44, 45 and 42 falls under another cluster. Based on per se performance genotype vizNP-09-43, Np-09-41, NP-09-46 and NP-09-49 recorded highest yield per hector and medium duration genotype recorded as NP-09-45 and 47. Hence, it can be considered that high yielding genotypes are grouped under Its cluster while in second cluster medium yielding genotypes are grouped representing high genetic diversity among the germplasm.

\section{Introduction}

Pigeonpea (Cajanus cajan (L.) Millspaugh) $(2 \mathrm{n}=22)$ is the second most important pulse crop of India after chickpea, commonly known as arhar, redgram and tur. Pigeonpea/ redgram is a grain legume belonging to the Cajaninae sub-tribe of the economically important leguminous tribe Phaseoleae. Based on the natural genetic variability in local germplasm and the presence of numerous wild relatives, Van der Maesen (1990) concluded that India is probably primary centre of origin. Pigeonpea is an important pulse crop that performs well in semi-arid tropics where moisture availability is unreliable or inadequate (Reddy et al., 1993). India is the largest producer of pigeonpea in the world sharing approximately $70 \%$ of the production and covering $74 \%$ of the area. Pigeonpea has a unique place in Indian farming and India accounts for about $90 \%$ of the global production. It is the second most important pulse crop next to chickpea, covering an area of around $4.42 \mathrm{~m}$ ha (occupying about $14.5 \%$ of area under pulses) and production of $2.86 \mathrm{mt}$ (contributing to $16 \%$ of total pulse production) and productivity of about $707 \mathrm{~kg} / \mathrm{ha}$ (FAOSTAT, 2011). Although India leads the world both in 
area and production of pigeonpea, its productivity is lower than the world average. One of the factors responsible for the poor productivity of pigeonpea is the lack of improved cultivars. Research for genetic improvement of this crop is required to raise yield levels effectively through widening genetic base. Information on genetic divergence among the plant materials is vital to a plant breeder for an efficient choice of parents for hybridization. It is an established fact that genetically diverse parents are likely to contribute desirable segregants and or to produce high heterotic crosses. Hence, this study is planned to study variability, genetic divergence and characterization of redgram germplasm at NARP, Agricultural Research Station, Navsari Agriculture University, Bharuch

\section{Materials and Methods}

The experiments for the present study were conducted in the NARP, Agricultural Research Station, Navsari Agriculture University, Bharuch Kharif 2019. The experimental material omprised of 10 pigeonpea germplasm. The experiment was laid out in Randomised Block Design with two replications. Observations were recorded for eight quantitative traits. They are days to maturity (DM), plant height $(\mathrm{PH})$ measured in $\mathrm{cm}$, number of branches per plant (NBP), number of pods per plant (NBP), and seed yield kg per hector (YPH). The morphological character i.e. coloure of the seed coat was noted to distinguish the genotypes from each other. R version 3.1.3 package 'gplots' was used to draw heat map for diversity study. Hierarchical clustering and heatmap analysis were performed for mean-centered and standardized data in $\mathrm{R}$. The 'hclust' function was used for hierarchical clustering. Heatmap.2 function used to draw heatmap' for given genotypes and traits analysed.
The genotype which matures within the range of 150-160 days is considered as medium duration genotype. The different variability parameters like mean, minimum, maximum is presented in table 1 .

\section{Results and Discussion}

In India, medium duration genotypes are mostly preferred among the pigeonpea growing farmers.

Days to maturity (DM), plant height $(\mathrm{PH})$ measured in $\mathrm{cm}$, number of branches per plant (NBP), number of pods per plant (NBP), and seed yield $\mathrm{kg}$ per hector (YPH) For plant height the range was recorded from $109 \mathrm{~cm}$ to $161 \mathrm{~cm}$, for number of branches it is varying from 14 to 22 . In case of days to maturity it is 125 days to 185 days which means great variation among genotype like short duration NP-09-42 and NP-09-48 long duration is present It is interesting to note that the average mean of genotype falls under medium duration. Two genotypes NP_09-47 and NP09-45 falls under medium duration category in present study. The range for yield for hector is 915 to $1523 \mathrm{~kg} / \mathrm{ha}$. Wide range for seed yield per hector is recorded among the genotypes. The highest yield was recorded for genotype NP_09-43 followed by NP-09-41, NP-09-46 and NP-09-49 respectively. These genotypes proved good yielder than the others and can be utilized in future breeding programme. Only two genotypes i.e. NP-0941 and NP-09-46 recorded white colour and the same genotypes are identified as high yielder too. While other genotypes are light, reddish or dark brown in colour. Similar results were being reported by Upadhyaya et al., (2007) and Manyasa et al., (2008) for growth habit, base flower color, pattern of streaks, pod colour, pod form and seed color pattern. These traits can be used for identifying individual germplasm. Other objective of the present study was to identify 
the high yielding and medium duration genotypes through cluster analysis. Hierarchical clustering of genotypes based on the Euclidian distances for the eight traits is represented. Heat map approach gives an opportunity to visualize the expression of the each trait in particular the environments. Heat map and dendrogram displaying relatedness of genotypes and traits under study based on their Euclidean distances. Red and yellow correspond to low and high diversity for expressed traits. White colour represents median levels of expression. The color key indicates the correlation between diversity and colors. The histogram represents a distribution of each value under observation for particular trait. Based on the Ward's clusters analysis (Squared Euclidean distance). The dendrogram of 10 genotypes of Pigeonpea is presented in Fig.1. Ten genotypes were grouped into two major clusters. Five genotypes grouped under Ist cluster and the another five genotypes grouped under IInd cluster.

Table.1 The mean performance of the genotype along with the Colour of the seed coat trait

\begin{tabular}{|l|c|c|c|c|c|l|}
\hline Genotypes & PH $(\mathbf{c m})$ & NBP & DM & NPP & YPH(kg/ha) & Seed coat coloure \\
\hline NP-09-41 & 149 & 22 & 169 & 238 & 1498 & white \\
\hline NP-09-42 & 119 & 14 & 125 & 251 & 915 & Light brown \\
\hline NP-09-43 & 161 & 19 & 165 & 357 & 1523 & Dark brown \\
\hline NP-09-44 & 154 & 18 & 168 & 272 & 1081 & Reddish brown \\
\hline NP-09-45 & 142 & 17 & 158 & 281 & 1185 & Light brown \\
\hline NP-09-46 & 159 & 19 & 172 & 384 & 1448 & White Reddish \\
\hline NP-09-47 & 112 & 16 & 158 & 387 & 1432 & Brown \\
\hline NP-09-48 & 158 & 20 & 185 & 285 & 913 & Light brown \\
\hline NP-09-49 & 149 & 17 & 178 & 363 & 1388 & Brown Reddish \\
\hline NP-09-50 & 109 & 16 & 165 & 342 & 1232 & Brown \\
\hline Mean & 141 & 17 & 164 & 316 & 1264.5 & \\
\hline Max & 161 & 22 & 185 & 387 & 1523 & \\
\hline Min. & 109 & 14 & 125 & 238 & 915 & \\
\hline
\end{tabular}

Fig.1 The dendrogram of ten pigeonpea germplasm showing diversity among the pigeonpea genotypes

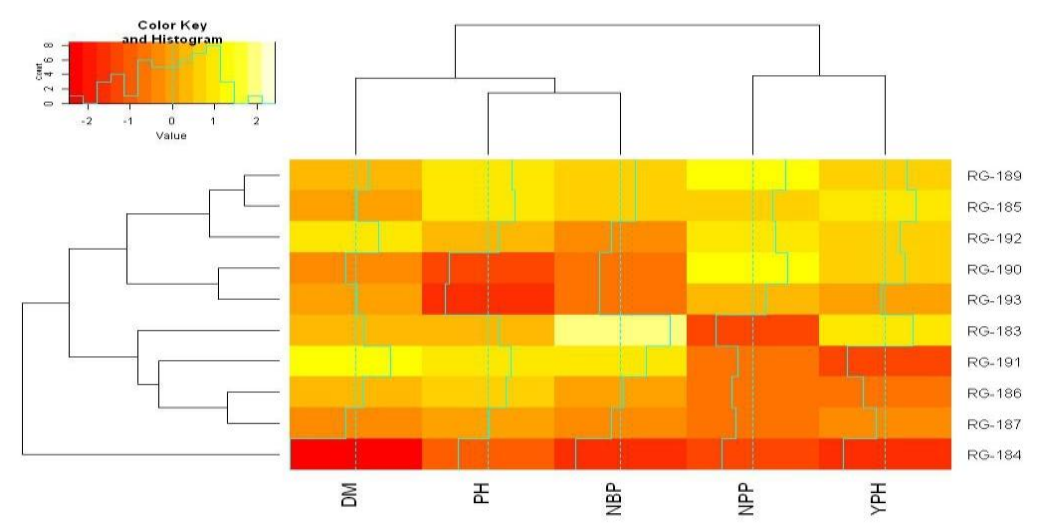


NP-0946, 43, 49, 47 and 50 falls under first cluster while NP-09-41, 48, 44, 45 and 42 falls under another cluster. Based on per se performance genotype viz., NP-09-43, NP-0941, NP-09-46 and NP-09-49 recorded highest yield per hector and medium duration genotype recorded as RG-187 and 190. Hence, it can be considered that high yielding genotypes are grouped under Ist cluster while in second cluster medium yielding genotypes are grouped representing high genetic diversity among the germplasm. Earlier in pigeonpea Thombre et al., (2000), Rekha et al., (2011), Praveen Pandey et al., (2013) and Rupika and Bapu (2014) studied genetic divergence either in among working germplasm and identified most divergent genotypes for the yield and yield attributing traits in redgram.

Use of diverse parents in hybridization programme can serve the purpose of combining desirable genes or to obtain recombination.

Crosses between divergent parents usually produce greater heterosis than those between closely related ones hence, identified genotypes can be utilised for the development of high yielding and medium duration varieties in pigeonpea.

\section{References}

Bohra, A., Saxena, Ganesh, B. N., Saxena K. B., Byregowda , M. and Rathore,A. 2012. An intra-specific consensus genetic map of pigeonpea (Cajanus cajan (L.) Millsp) derived from six mapping populations. Theor. Appl. Genet., 125: 1325-1338.
FAOSTAT. 2011. FAOSTAT. FAO, Rome, Italy. http://faostat.fao. org/

Manyasa. E. O., Silim, S. N., Githiri, S. M., and Christiansen, J. L. 2008. Diversity in Tanzanian pigeonpea (Cajanus cajan (L.) Millsp.) land races and their response to environments. Genet. Resour. Crop Evol.,55:379-387.

Praveen Pandey., Rajesh Kumar., Vankat Raman Pandey and Mritunjay Tripathi. 2013. Genetic divergence studies in pigeonpea (Cajanus cajan (L.) Millsp.) American J. Plant Sci., 4: 2126- 2130.

Rekha, R., Prasanti, L., Reddi Sekhar, M., Latha P. and Sudhakar, S. 2011. Genetic diversity in pigeonpea (Cajanus cajan (L.) Millsp.). Legume Res., 34(2): 139-142

Reddy, M.V., Raja, T.N., Sharma, S.B., Nene, Y.L. and McDonald, D. 1993. Handbook of pigeonpea diseases. ICRISAT Information Bulletin No. 42. Patancheru 502 324, Andhra Pradesh, India: International Crops Research Institute for the Semi-Arid Tropics.

Rupika, and J. R. Kannan Bapu. 2014. Assessment of genetic diversity in pigeonpea germplasm collection using morphological characters $K$. Electronic Journal of Plant Breeding, 5(4): 781-785

Thombre, B.B., Aher, R.R and Dahat. D.V.2000. Genetic divergence in pigeon pea. Indian J. Agric. Res., 34: 126-129.

Upadhyaya H. D., Reddy, K. N., Gowda and Sube Singh C. L. L. 2007. Phenotypic diversity in the pigeonpea (Cajanus cajan) core collection. Genet. Resour Crop Evol.,54:1167-1184.

Van der Maesen, L.J.G. 1990. Pigeonpea: Origin, history, evolution and taxonomy. In Pigeonpea. Edited by: Nene YL, Hall SD, Sheilla VK. Wallingford: CAB International; 1990:15-46.

\section{How to cite this article:}

Patel, H. N. and Patel, D. G. 2020. Genetic Diversity and Characterization of Pigeon Pea Germplasm. Int.J.Curr.Microbiol.App.Sci. 9(12): 3493-3496.

doi: https://doi.org/10.20546/ijcmas.2020.912.414 